Laut Statuten ist jedes Mitglied berechtigt, einzelne Vorschläge für die Wahl der Präsidentin / des Präsidenten bzw. der beiden Stellvertreterlnnen einzubringen (Vorschlag eines Teams). Die Zustimmung der Vorgeschlagenen ist einzuholen. Die Vorschläge können bis zum 21. Oktober 2021 dem Sekretariat (sekretariat@voeb-b.at) übermittelt werden. Später einlangende Vorschläge können nicht berücksichtigt werden.

\title{
WAHL DES VORSTANDS FÜR DIE FUNKTIONSPERIODE BIS 2023
}

Anlässlich der Generalversammlung, die am 18. November 2021 in Wien stattfinden wird, wird der Vorstand der Vereinigung Österreichischer Bibliothekarinnen und Bibliothekare neu gewählt. Statutengemäß besteht der Vorstand aus allen Mitgliedern des Präsidiums, den Vorsitzenden der Kommissionen für die Dauer ihrer Funktion, je einer Vertreterin/einem Vertreter verwandter Berufsvereinigungen Österreichs, mit denen ein entsprechendes Abkommen besteht, und weiteren zu wählenden Vereinsmitgliedern.

Die VÖB lädt ihre Mitglieder daher ganz herzlich dazu ein, Ihr Engagement für unsere Vereinigung auch dadurch zu dokumentieren, dass Sie sich dieserWahl stellen und dem Sekretariat (sekretariat@voeb-b.at) bis 21. Oktober 2021 Ihre Kandidatur bekanntgeben. Bitte fügen Sie Ihrer Bewerbung eine Kurzbiographie in Stichworten und ein Foto bei.

DOI: https://doi.org/10.31263/voebm.v74i2.6390

(c) Vereinigung Österreichischer Bibliothekarinnen und Bibliothekare

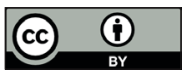
Dieses Werk ist - exkl. einzelner Logos und Abbildungen - lizenziert unter einer Creative-Commons-Lizenz Namensnennung 4.0 International-Lizenz 